\title{
Theoretical analysis and experiment study of balanced type variable vane pump \\ Zhang Pan ${ }^{1, a}$, Chen Lei $\mathrm{i}^{2, \mathrm{~b}}$
}

\author{
${ }^{1}$ High tech college, Shanghai Maritime University, Shanghai China \\ ${ }^{2}$ Merchant college, Shanghai Maritime University, Shanghai China \\ apennyzhang@163.com, bclinfo@eyou.com
}

Keywords: balanced vane pump; floating block; dynamic; energy saving

\begin{abstract}
To take account of the fact for an automotive hydraulic power steering system have serious energy loss, this paper discusses the configuration and the action principle of a new variable displacement of double-action vane pump, which consists of a floating block and rate compensation characteristics. In addition the dynamics formulation of the variable machine is studied. The model of variable is developed and equation of flux is performed. The test of the mechine is performed. The results show that the pump with the floating block can reduce the energy efficiently and prosperous utilization is expected.
\end{abstract}

\section{Introduction}

At present the international crude oil price is rising up, reducing oil consumption needs more and more attention around the world. Reducing energy consumption is becoming the focus of attention in the world; it was particularly conspicuous in the field of automotive technology. In the past operation, researchers put their main attention on how to reduce the energy consumption in engine and transfer motion system, but not in auxiliary system such as steering system. Go through the research we can see, steering system uses up 3\% energy of engine. While automobile is driving, the motor's speed is more than idling at most time, And more than $80 \%$ of the time in a straight line or a wait state, therefore, the oil pumped output flows back into the storage tank after the flow control valve and the steering control valve, gave rise to great energy loss ${ }^{[1]}$. This paper presents a new balance type variable vane pump with floating blocks on the basis of patented technology ${ }^{[2]}$, this pump has the characteristics of speed compensation, can effectively reduce the energy consumption of hydraulic steering system, and it is an ideal vehicle steering pump compared with the traditional steering pump.

\section{The basic structure and working principle}

\section{Basic structure of the balance type variable vane pump}

Balance type variable vane pump is taken shape from balance type available vane pump by improving certain structure, which is mainly composed of stator,rotor,vane,oil inlet,oil outlet, floating block and connecting spring etc, the stator is set in the hull, and the rotor is put in the stator. 12 groups of vane is distributed on rotor evenly, 12 groups of floating block are put between two adjacent vanes. The floating block is structured by a block and a connecting spring, the block is installed in the block trough, and the connecting spring is set in the spring trough.

\section{Description of the balance type variable vane pump working principle}

The variable principle of balance type variable vane pump is the block of the floating block is elastic in the trough in the rotor. Decided by the different speed of the rotor, the block can slither in the block trough, the space taken by the block has a bearing on the speed of the pump, so the pump is variable. When the rotor speeds up the blocks consume more space, at the same time the oil inlet the pump reduces. When the rotor speed is reduced, floating block experience within shift, pump the effective volume of the space, the pump per turn, absorbing oil content increase ${ }^{[3]}$. 


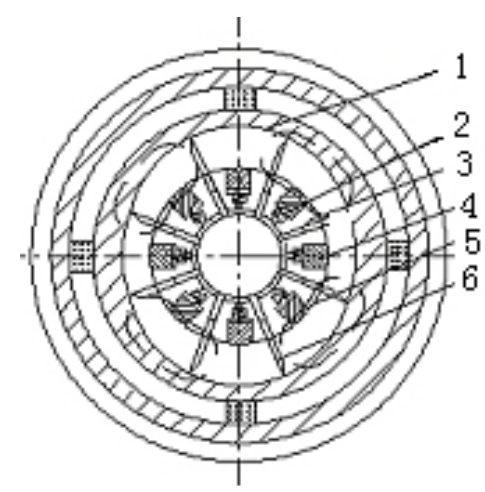

Fig 1 Structure diagram of balance type variable vane pump

1. stator 2.spring 3.rotor 4.block 5.block trough 6.vane

\section{Prototype test}

In order to verify balance type variable vane pump based on the velocity compensation principle feasibility and prototype flow equation is correct, according to the balance type variable vane pump design drawings processing vane pump prototype, In Dalian hydraulic factory vane pump performance test system for performance test bench.

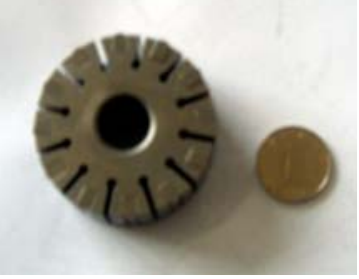

Fig.2 Prototype parts diagram

The original parameters of balance type variable vane pump is based on V20NF pump batch produced by Dalian hydraulic factory, refer to the performance parameters of V20NF pump: $q=22.1 \mathrm{ml} / \mathrm{r} ; P=10 \mathrm{MPa} ;{ }^{n}=500 \sim 3000 \mathrm{r} / \mathrm{min}$, and the Mechanical design drawing of V20NF pump, to define balance type variable vane pump's basic structure and main components of the quantity, size [6]. We design the variable mechanism for floating block as $4.5 \mathrm{~mm}$ width, $6.2 \mathrm{~mm}$ height $22.0 \mathrm{~mm}$ depth,the block has an arc top which radius is $2.5 \mathrm{~mm}$, and $0.8 \mathrm{~mm}$ angle of chamfer,the block trough is designed as $4.5 \mathrm{~mm}$ width, $6.2 \mathrm{~mm}$ height $22.0 \mathrm{~mm}$ depth. The rotor spring hole's diameter is $4.0 \mathrm{~mm}$. Connecting spring adopts a cylindrical helical tension spring, whose diameter is $0.5 \mathrm{~mm}$, spring diameter design for $3.0 \mathrm{~mm}$. Schematic structure as shown in figure 4.Stator vane pump long radius $31.6 \mathrm{~mm}$, short radius $28.5 \mathrm{~mm}$, the thickness of $22.0 \mathrm{~mm}$; leaf thickness is $1.7 \mathrm{~mm}$, blade number is 12, blade angle is 0 degrees; a rotor diameter of $57.5 \mathrm{~mm}$.

All the test results with 46 of hydraulic oil, to actuate the motor was used to drive the pump rotate preheating temperature is $50{ }^{\circ} \mathrm{C}$, the load condition by measuring pump output flow results. At the same time, Dalian hydraulic parts factory production V20NF quantitative pump does comparative test, measurement of different rotational speeds of the quantitative pump output flow value and balance type variable vane pump prototype output flow value comparison, verification of balance type variable vane pump prototype effects on energy saving and speed compensation effect.

V20NF quantitative pump and balance type variable vane pump test output flow diagrams are shown in fig.3, fig4. and fig. 5 describes the theory of balance type variable vane pump prototype output flow diagram.

By balance type variable vane pump instead of quantitative pump, this gave the energy-saving type automobile steering pump is provided for generating conditions. If the speed change and flow variations induced by itself, through the vane pump variable mechanism to change the pump displacement, compensating speed increases the output flow, reduce excess flow generation reduces the consumption of reactive power steering pump. In the high speed, prototype and quantitative pump output flow difference is bigger, achieve the same speed reducing the overflow purpose in 
overflow valve. To reduce energy loss caused by the steering system as the pump itself redundant flow, energy saving effect is obvious.

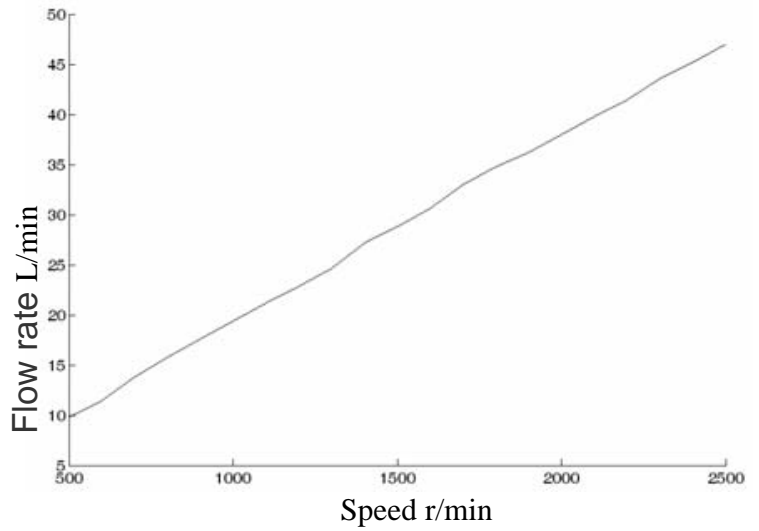

Fig.3 V20NF quantitative pump test output flow diagram

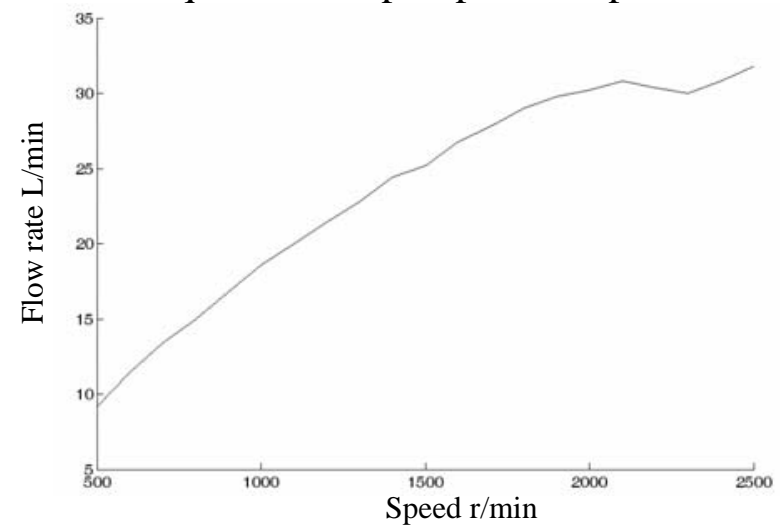

Fig.4 Balance type variable vane pump test output flow diagram

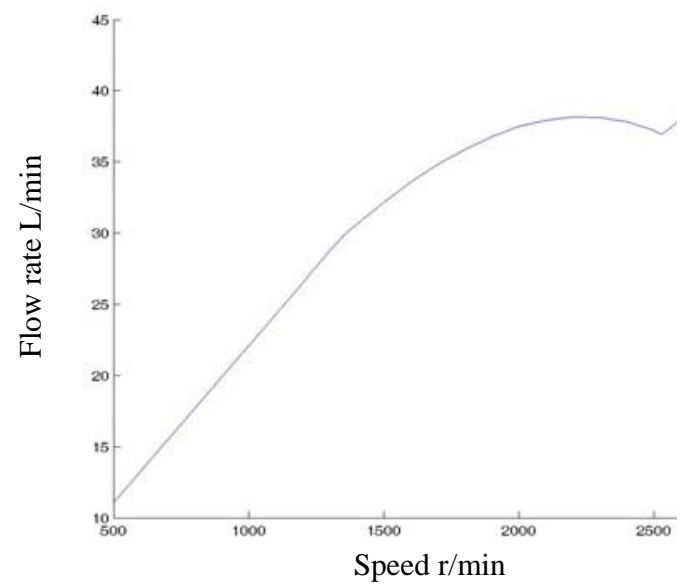

Fig.5 Theory of balance type variable vane pump prototype output flow diagram

\section{Conclusions}

Balance type variable vane pump is a kind of speed compensation balance type vane pump, which is a new-style steering pump, belongs to the field of transport in power for automobile power steering and the other operating conditions. Establish the balance type variable vane pump variable mechanism dynamics model and the output flow equation, then processing prototype output flow bench test. The results showed that: prototype flow output curve and the theoretical equations for calculation of flow curves are almost same. New balance type variable vane pump can effectively reduce the redundant output flow, reduce the energy loss of steering system, and lay good foundation for the next step for the improvement of prototype development. 


\section{References}

[1] LIU Guangsong. Analyzing energy dissipating character of hydraulic power steering system [J]. Shanxi Machinery, 2002,17(4);5-7.

[2] CHEN Lei, LI Xihe, CHEN Haiquan, SUN Yuqing. Energy saving of variable displacement balanced vane pump[J]. Journal of Dalian Maritime University, 2007, 33(2):106-110.

[3] Xue Xiaohu. "Analysis on the Fluid-leakage Characteristic in Gaps of the Hydraulic System”, Chinese Journal of Mechanical Engineering, 2004, 40(6):75-80

[4] Yoshiharu Inaguma,Kazuhiro Watanabe and Hideya Kato“Energy-saving and Reduction of Oil TemPerature Rising in Hydraulic Power Steering System”.SAE paper 1999-01-0392,Toyoda Machine works,Ltd.Akira Hibi,Toyohashi University of Technology.1999

[5] Gao Xiang, Zhao Jincai, Wang Ruoping, Ling Zhiyong. "Simulation Analysis on Hydraulic Power Assisted Steering System”, Journal of Jiangsu University (National Science Edition), 2003, 24(6):34-38

[6] Eiichi Kojima. "Development Of A Quieter Variable Displacement Vane Pump For Automotive Hydraulic Power Steering System”, International Journal of Fluid Power, (4): 5-14. (2006) 